\title{
Noninvasive multianalyte diagnostic assay for monitoring bladder cancer recurrence
}

\author{
This article was published in the following Dove Press journal: \\ Research and Reports in Urology \\ 17 October 2012 \\ Number of times this article has been viewed
}

\author{
Neal D Shore' \\ Cecilia A Fernandez ${ }^{2}$ \\ Anthony P Shuber ${ }^{2}$ \\ 'Carolina Urologic Research Center/ \\ Atlantic Urology Clinics, Myrtle \\ Beach, SC, ${ }^{2}$ Predictive Biosciences Inc, \\ Lexington, MA, USA
}

Background: The purpose of this study was to establish the clinical performance of a urine-based assay, called a multianalyte diagnostic readout, in monitoring for bladder cancer recurrence.

Methods: This was a prospective, multicenter, single assessment observational study. The multianalyte diagnostic readout uses a combination of one protein and three DNA biomarkers. Urine samples from 733 patients undergoing monitoring for bladder cancer recurrence were analyzed for matrix metalloproteinase-2 levels, the presence of mutant FGFR3 DNA, and hypermethylation of the NID2 and VIM genes. The probability of a patient having (positive predictive value) or not having (negative predictive value) recurrent bladder cancer was determined by FGFR3 alone or all four biomarkers combined, respectively.

Results: Cystoscopy/biopsy diagnosed 63 patients with bladder cancer recurrence at the time of study assessment. The four-biomarker assay identified 237 patients as having a low probability of disease recurrence, 231 of whom were determined by cystoscopy as not having recurrent cancer, resulting in a negative predictive value of $97.5 \%$ at $90.5 \%$ sensitivity. The FGFR 3 assay identified 49 patients with FGFR3 mutations, 19 of whom were confirmed by biopsy as having cancer, resulting in a positive predictive value of $38.8 \%$, with $95.5 \%$ specificity.

Conclusion: The urine-based multianalyte diagnostic readout assay was able to delineate the patient population into those highly likely to have bladder cancer recurrence, those unlikely to have recurrent disease, and those with an average risk for bladder cancer recurrence.

Keywords: FGFR3, matrix metalloproteinase-2, NID2, VIM, recurrent bladder cancer

\section{Introduction}

Bladder cancer is the seventh leading cause of death in the US, and the disease was estimated in 2008 to cause about 150,000 deaths worldwide. ${ }^{1}$ The majority of bladder cancer patients present with disease that does not invade muscle, with an estimated recurrence rate in this group of patients being $>50 \%$. $^{2}$ About $10 \%-30 \%$ of this patient population will have recurrent disease which progresses to muscle invasion within 5 years. ${ }^{3,4}$

Due to the risk of recurrence and progression, established guidelines recommend that patients with nonmuscle-invasive bladder cancer should be monitored after initial diagnosis and treatment. ${ }^{5,6}$ The American Urological Association and National Comprehensive Cancer Network recommend surveillance every 3-6 months for 3 years and at least yearly thereafter. ${ }^{7}$ Surveillance for patients who have been treated for nonmuscle-invasive bladder cancer may include urine cytology, imaging, cystoscopy, and biopsy. ${ }^{6}$ 
Currently, two major assays for detecting bladder cancer are based on cystoscopy and biopsies. Cystoscopy has been considered the "gold standard" surveillance diagnostic modality for nonmuscle-invasive bladder cancer, and requires a degree of invasiveness, as well as both clinician-related and patient-related time commitment and expense. ${ }^{8}$ Moreover, iatrogenic injury to the urethra and bladder as well as risk of infection may ensue. ${ }^{8}$ Currently approved biomarkers for detecting bladder cancer rely on a single quantitative cutoff, above which a patient is defined as having cancer and below which a patient is defined as cancer-free. Single cutoff assays attempt to maximize sensitivity and specificity simultaneously; neither value is optimal and may result in many false-positive or false-negative results, ${ }^{9}$ thereby falling short of providing clinically relevant information. ${ }^{10}$ For example, for a biomarker assay with $80 \%$ sensitivity and $80 \%$ specificity, $20 \%$ of the positive samples will not have cancer and likewise $20 \%$ of negative samples will have cancer, creating ambiguity in the results.

A urine-based multianalyte diagnostic readout assay has been developed that combines the performance of one protein (matrix metalloproteinase-2, MMP-2) and three DNA (Nidogen 2 [NID2], Vimentin [VIM], and fibroblast growth factor receptor 3 [FGFR3] gene) markers for identifying patients with a high likelihood (positive predictive value, PPV) or low likelihood (negative predictive value, NPV) of having recurrent bladder cancer. The multianalyte diagnostic readout assay uses two cutoffs, one to achieve high NPV and another to achieve high PPV. The combined biomarkers were used to achieve a high NPV, and FGFR3 alone was used to obtain a high PPV.

The important premise, and associated clinical implication, is designing an assay with high NPV and high sensitivity, which would identify patients with a low probability of having the disease, as well as an assay with a high PPV and high specificity which would identify patients with a high probability of having the disease and who would thus require additional intervention. The multianalyte biomarker readout assay is used to identify patients unlikely to have bladder cancer at the given monitoring visit; a patient is considered not to have the disease if all biomarkers are negative. In prior studies, we have shown that FGFR 3 has high specificity and PPV, and may be used to identify patients with a high probability of having bladder cancer; patients are categorized as having the disease if their urine contains mutant FGFR3 DNA. ${ }^{11,12}$ The remaining patients are at average risk for recurrence and would continue to receive the standard of care, which includes routine surveillance by cystoscopy ${ }^{5,13}$ and possibly cytology and other biomarkers.

\section{Materials and methods}

This was a prospective, observational, multicenter, single assessment, diagnostic study evaluation designed to assess the performance characteristics of the multianalyte biomarker readout assay relative to routine surveillance cystoscopy to detect recurrent bladder cancer. Patients were recruited from 29 independent urology or oncology practices performing follow-up cystoscopy for bladder cancer. The study was conducted according to the principles established by the Declaration of Helsinki. Appropriate institutional review boards approved the protocol and all patients gave their written informed consent.

\section{Study patients}

Eligible patients were $\geq 18$ years of age, had a history of nonmuscle-invasive bladder cancer, and were undergoing routine bladder cancer recurrence screening by cystoscopy for $\geq 3$ months and $\leq 3$ years post initial urothelial bladder cancer treatment and/or not $>3$ years from the most recent diagnosis of bladder cancer recurrence.

One group of samples from the entire study population was chosen at random and used to determine cutoffs (derivation population, $\mathrm{n}=271$ ). The second group, consisting of the remaining patient samples, was used to test assay efficacy (validation population, $\mathrm{n}=733$ ). Random selection ensured that the patient populations were comprised of samples obtained from the various clinical sites and were representative of the entire study population having similar demographics and clinical characteristics.

\section{Study design}

At the study visit, urine samples and baseline values, including age, gender, and smoking status, were collected and cystoscopy was performed. A patient was considered negative for bladder cancer if cystoscopy showed no evidence of disease or if a biopsy was performed and the biopsy was negative for cancer. All patients were considered positive for recurrence if the finding of cancer was confirmed by histopathology. Patients with indeterminate cystoscopy findings were sent for biopsy and then categorized as positive if the biopsy was positive or no evidence of disease if the biopsy was negative. In cases where a biopsy result was missing, the patient was excluded from further analysis. 
The multianalyte biomarker readout assay was performed and evaluated with regard to the clinical cystoscopy and biopsy diagnosis in a blinded manner. Urine samples were collected using a standard clean catch protocol prior to cystoscopy and stored at $-80^{\circ} \mathrm{C}$. Samples for DNA analysis were stabilized with $25 \mathrm{mM}$ ethylenediamine tetra-acetic acid. Genomic DNA was isolated from the urine samples (4 $\mathrm{mL}$ ) using the QIAamp MinElute virus vacuum kit (Qiagen, Hilden, Germany) according to the manufacturer's instructions, and stored at $-20^{\circ} \mathrm{C}$.

\section{MMP-2 protein quantitation}

MMP-2 urine protein levels were quantified by enzymelinked immunosorbent assay (R\&D Systems, Minneapolis, $\mathrm{MN}$ ) using $50 \mu \mathrm{L}$ of neat urine, as per the manufacturer's instructions. Samples were assayed in duplicate.

\section{FGFR3 mutation assay}

Genomic DNA isolated from $4 \mathrm{~mL}$ of urine was amplified using oligonucleotide primers specific for human FGFR3 to amplify DNA from exons 7, 10, and 15 (Supplemental Table 1). Polymerase chain reaction (PCR) amplification was performed using a Bio-Rad $\mathrm{C} 1000$ thermal cycler under the following conditions: 10 seconds at $95^{\circ} \mathrm{C}, 30$ seconds at $65^{\circ} \mathrm{C}$, and 10 seconds at $72^{\circ} \mathrm{C}$ for 50 cycles. DNA amplification was confirmed by agarose gel analysis of primary PCR products.

FGFR3 mutations were detected utilizing a PCRclamping methodology. Wild-type blocking oligonucleotides containing locked nucleic acid bases surrounding known mutation sites were included, along with real-time PCR primers and dual-labeled Taqman probes (Supplemental Table 1). The locked nucleic acid primers, which have a higher annealing affinity with wild-type than mutant DNA, inhibit wild-type DNA elongation, resulting in preferential amplification of mutant DNA. PCR was performed in the absence of primers containing locked nucleic acid to control for levels of DNA in each reaction. Real-time PCR amplification was performed using a Roche Light Cycler

Table I Summary of derivation population performance characteristics $^{\mathrm{a}}$

\begin{tabular}{llll}
\hline & Sensitivity & NPV & Specificity \\
\hline $\begin{array}{l}\text { NID2, FGFR3, VIM, } \\
\text { and MMP-2, n (\%) }\end{array}$ & $85(4 \mid / 48)$ & $96(I 53 / 160)$ & $67(I 53 / 229)$ \\
$95 \% \mathrm{Cl}$ & $72-94$ & $91-98$ & $60-73$ \\
\hline
\end{tabular}

Notes: aCutoffs for the different biomarkers were: MMP-2 $<1.100 \mathrm{ng} / \mathrm{mL}$, NID2 $<600 \mathrm{~K}$, and Vimentin $<0.19 \mathrm{ng}$. For FGFR3, a patient is either positive or negative for mutant DNA.

Abbreviations: $\mathrm{Cl}$, confidence interval; NPV, negative predictive value. real-time thermal cycler $\left(10\right.$ seconds at $95^{\circ} \mathrm{C}, 30$ seconds at $60^{\circ} \mathrm{C}$, and 10 seconds at $72^{\circ} \mathrm{C}$ for 50 cycles). Samples were excluded from analysis if there was not sufficient input DNA as determined during the initial PCR reaction. The ratio of amplification cycles of positive controls (plasmids containing known FGFR3 mutations) to negative controls (wild-type DNA) were used to assess if a sample did or did not contain a mutation. All PCR reactions were performed in duplicate.

\section{NID2 and VIM methylation analysis}

Methylation of NID2 DNA was evaluated using conventional methylation-specific PCR. A maximum of $2 \mu \mathrm{g}$ of genomic DNA purified from $8 \mathrm{~mL}$ of urine was bisulfite-converted using the Epitect bisulfite kit (Qiagen) following the manufacturer's instructions. The resulting converted DNA was eluted into $30 \mu \mathrm{L}$ of molecular grade $\mathrm{H}_{2} \mathrm{O}$ and stored at $-20^{\circ} \mathrm{C}$. Conventional methylation-specific PCR was performed using methylation-specific primers to the NID2 promoter (Supplemental Table 1) in the Bio-Rad C1000 thermal cycler $\left(10\right.$ seconds at $95^{\circ} \mathrm{C}, 10$ seconds at $60^{\circ} \mathrm{C}$, and 10 seconds at $72^{\circ} \mathrm{C}$ for 50 cycles) and the methylation threshold determined by densitometry.

Methylation of VIM was evaluated using quantitative real-time methylation-specific PCR from DNA prepared as described above. Quantitative real-time methylation-specific PCR was performed using methylation-specific primers and probes (Supplemental Table 1) to the VIM promoter region in the Roche Light Cycler 480 (Roche, Basel, Switzerland) under the following conditions: 60 seconds at $95^{\circ} \mathrm{C}, 60 \mathrm{sec}-$ onds at $65^{\circ} \mathrm{C}$, and 60 seconds at $72^{\circ} \mathrm{C}$ for 50 cycles. A standard curve was included in all VIM assays to determine the amount of methylated VIM DNA present in each sample.

To ensure that a negative result for either gene was accurate, a minimum input of 20 ng of DNA, as determined by quantitative real-time methylation-specific PCR amplification of unmethylated $A C T I N-B$, was required. Samples negative for hypermethylation that did not meet the minimum DNA inputs were excluded from further analysis.

\section{Statistical analysis}

The primary endpoint was to test the ability of the multianalyte biomarker readout assay to evaluate a patient population undergoing monitoring for bladder cancer recurrence using the two cutoff approach, where one cutoff included all markers and the other cutoff included only FGFR3. Performance of the combined biomarker assay focused on sensitivity and NPV for the purpose of identifying patients who were unlikely to have recurrent disease, and performance of FGFR3 alone focused 
on specificity and PPV for the purpose of identifying patients with recurrent disease. Statistics of categorical variables included number and percentage of subjects. Subgroup analysis included cancer stage and grade.

\section{Negative predictive value}

Assessment of NPV used a composite of cutoffs for all the biomarkers. Cutoff values were selected to achieve $\geq 95 \%$ NPV and approximately $90 \%$ sensitivity when in combination and as previously described by us. ${ }^{14} \mathrm{~A}$ patient was classified as negative if all biomarkers were negative. A patient was classified as positive/intermediate if one or more of the biomarkers did not meet the cutoff criteria. NPV was calculated as follows:

\section{NPV = True cystoscopy negative/All multianalyte biomarker readout assay negatives.}

\section{Positive predictive value}

Evaluation of PPV utilized FGFR3 mutational status. A patient was considered positive if their urine contained mutant FGFR3 DNA. A patient was considered indeterminate/ negative if the urine contained wild-type FGFR3 DNA. PPV was calculated as follows:

\section{PPV = True cystoscopy-biopsy positive/ All FGFR3 assay positives.}

\section{Results}

Of the 1153 patients enrolled in the study, 271 were used as the derivation population to establish the cutoff values for the multianalyte biomarker readout assay and 733 were analyzed as the validation population (Figure 1). A total of 149 samples were not evaluable due to incorrect consent forms, samples not received or damaged during shipping, or samples where at least one of the marker results were missing (Figure 1).

\section{Establishment of biomarker cutoffs: derivation population}

Four biomarkers were evaluated to determine what combination would give the highest sensitivity and NPV for the study endpoint. We have previously reported on a limited population trial evaluating the use of a DNA/ protein combination assay for patients undergoing recurrence monitoring. ${ }^{11}$ As with previous studies, the marker combination used here includes hypermethylation markers. Hypermethylation of VIM can also be detected in the urine of bladder cancer patients. ${ }^{15}$ Preliminary studies in our laboratory have shown that samples positive for one hypermethylation marker often overlap with samples that are positive for other hypermethylation markers tested (data not shown). In this study, the markers included the DNA biomarkers NID2, FGFR3, and VIM, and the protein marker, MMP-2. For the derivation population, 271 patients from this study were randomly chosen to establish cutoffs for the four biomarkers. Cutoffs for quantitative markers were established to achieve $\sim 90 \%$ sensitivity while maximizing specificity when in combination. To obtain maximum NPV at high sensitivity, we first applied binary markers, and then established cutoffs for the other markers one by one, as previously described. ${ }^{11}$ Of the 271 patients, 42 had

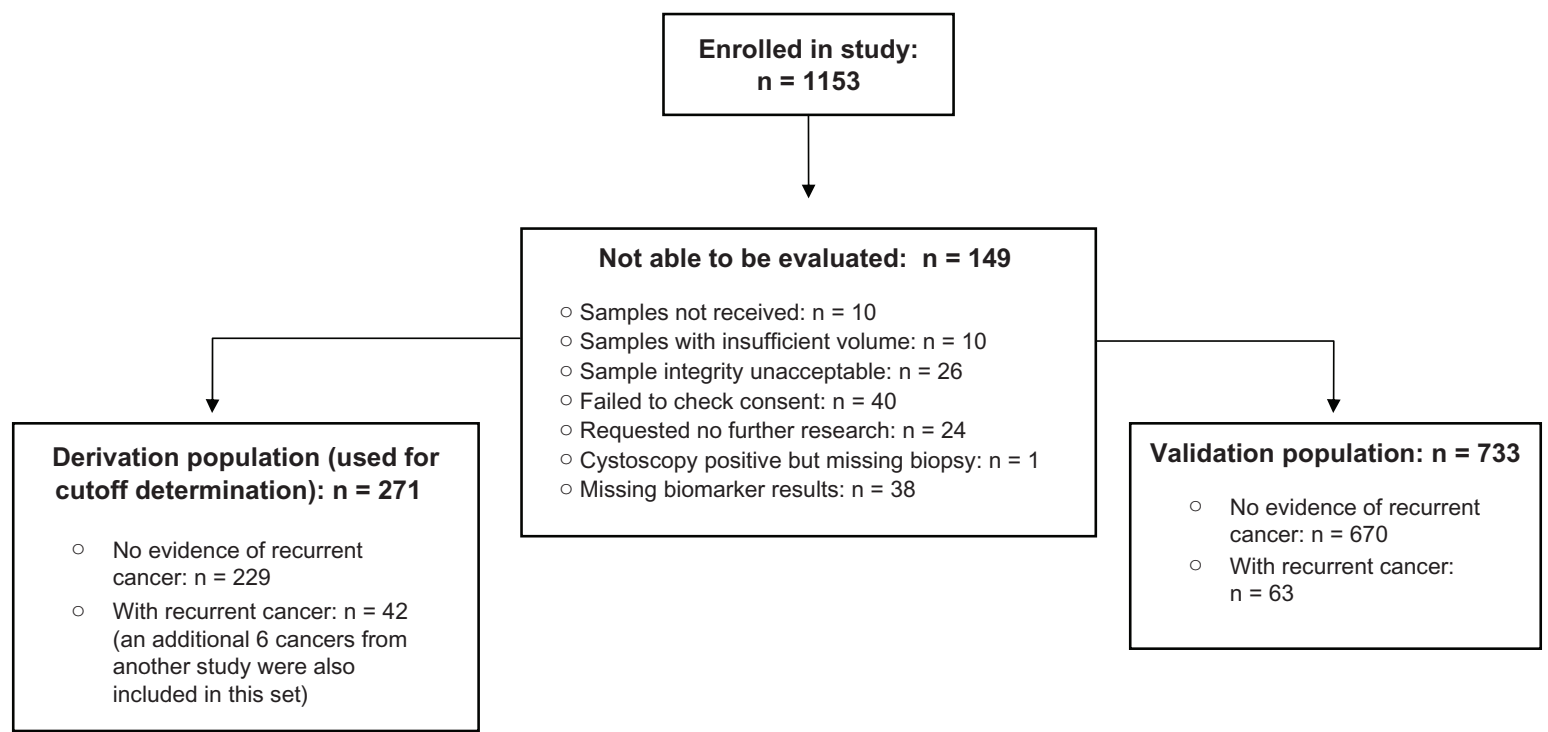

Figure I CONSORT diagram. 
recurrent cancer and the remaining 229 had no evidence of disease based on cystoscopy or biopsy. Six additional patients with bladder cancer from an independent study with demographics similar to those of the current study were included in the derivation population to increase the number of cancers.

The assay assessed the performance of the four biomarkers in combination to maximize sensitivity and NPV (Table 1). The optimal cutoffs for the individual markers were: MMP-2 < 1.100 ng/mL; VIM $<0.190$ ng; NID $2<60 \mathrm{~K}$; and FGFR3 = negative. FGFR3 was used to assess PPV, given that it has high specificity and is known to be associated with bladder cancer. ${ }^{16-20}$

\section{Validation population}

The validation population consisted of 733 patients; 670 $(91.4 \%)$ of the patients did not have recurrent bladder cancer and $63(8.6 \%)$ had documented recurrence as evidenced with cystoscopy/biopsy (Figure 1). Baseline demographics and disease characteristics were similar between the two patient groups (Table 2). The four-biomarker combination identified 237 patients as unlikely to have recurrent cancer, 231 of whom were confirmed not to have cancer by cystoscopy resulting in a NPV of $97.5 \%$ (Table 3 ) and a sensitivity of $90.5 \%$. In general, the results of the assay were not influenced by the grade and stage of the tumor (Table 4).

Cystoscopy/biopsy identified 63 patients with bladder cancer recurrence. Mutant FGFR3 DNA was present in the urine of 49 patients, 19 of whom were identified by cystoscopy/biopsy to have recurrent bladder cancer. These findings indicate that FGFR3 had a specificity of $95.5 \%$ with $38.8 \%$ PPV.

Table 2 Baseline demographics and disease characteristics

\begin{tabular}{lcl}
\hline Characteristic & $\begin{array}{l}\text { Biopsy positive } \\
(\mathbf{n}=63)\end{array}$ & $\begin{array}{l}\text { Biopsy/cystoscopy } \\
\text { negative } \\
(\mathbf{n}=670)\end{array}$ \\
\hline $\begin{array}{l}\text { Mean age, years } \pm \text { standard } \\
\text { deviation }\end{array}$ & $7 \mathrm{I} \pm \mathrm{II} .4$ & $69 \pm 10.9$ \\
$\begin{array}{l}\text { Male, n (\%) } \\
\text { Determination of disease diagnosis, } \mathrm{n}(\%)\end{array}$ & $513(76.6)$ \\
$\begin{array}{l}\text { Biopsy } \\
\text { Cystoscopy }\end{array}$ & $63(100.0)$ & $100(14.9)$ \\
Smoking status, n (\%) & 0 & $570(85.1)$ \\
Yes & $43(68.3)$ & $520(77.6)$ \\
No & $20(31.7)$ & $137(20.4)$ \\
Unknown & 0 & $13(1.9)$ \\
\hline
\end{tabular}

\section{Discussion}

This prospective, multicenter, single assessment, observational study evaluated the performance characteristics of the multianalyte diagnostic readout assay compared with cystoscopy in identifying recurrent bladder cancer. The assay used a combination of four biomarkers, ie, NID2, VIM, and FGFR3 DNA biomarkers, and the MMP-2 protein biomarker, to identify patients with a low probability of having recurrent bladder cancer. The FGFR3 assay has a high specificity for detecting mutant FGFR3 DNA in urine, and was used to detect patients with a high likelihood of having recurrent bladder cancer. The four-biomarker combination had an NPV of $97.5 \%$ for identifying patients unlikely to have recurrent disease. Importantly, the sensitivity and NPV of the assay was high across all stages and grades of tumors.

The combination of the three DNA-based biomarkers with the MMP-2 protein marker resulted in an assay with a sensitivity comparable with that of cystoscopy in detecting patients without bladder cancer, suggesting that this assay may identify patients who might be excluded from invasive diagnostic procedures at a given follow-up visit. Typically, either protein or DNA markers are multiplexed as independent marker sets. In contrast, in the multianalyte diagnostic readout assay, the biomarkers are combined into a protein-DNA multiplex format. Protein markers usually have high sensitivity due to the fact that the methods for measuring their presence are highly quantitative; however, these same methods are often limited in specificity. In contrast, DNA markers typically have high specificity (for example, a mutation is either present or not) but low sensitivity. This study found that combining protein and DNA markers into a multiplex format resulted in an assay that accurately identified patients unlikely to have recurrent bladder cancer. These findings are consistent with a prior study that evaluated the ability of a similar protein-DNA multiplexed assay to detect recurrent bladder cancer. ${ }^{11}$

FGFR3 mutations are prevalent in noninvasive low-grade tumors, and due to the high specificity of this biomarker, the presence of mutant DNA in a patient's urine is likely indicative of bladder cancer. ${ }^{16-20}$ In this study, FGFR3 mutations were detected in the urine of 19 of 63 patients who had cancer with high specificity (95.5\%) and with $38.8 \%$ PPV, higher than other markers when adjusted for prevelence. ${ }^{21}$ Although FGFR 3 was also positive in the urine of 30 patients who were negative for cancer by cystoscopy, it is possible that in the bladder cancer survivor patient population, the likelihood of an FGFR3-positive/cystoscopy-negative finding is higher than in other symptomatic populations. ${ }^{12}$ Given that bladder 
Table 3 Assay performance characteristics

\begin{tabular}{|c|c|c|c|c|}
\hline & Sensitivity & Specificity & NPV & PPV \\
\hline Combined four biomarkers, \% (n) & $90.5(57 / 63)$ & $34.5(231 / 670)$ & $97.5(23 \mid / 237)$ & - \\
\hline $95 \% \mathrm{Cl}$ & $80.4-96.4$ & $30.9-38.2$ & $94.6-99.1$ & - \\
\hline FGFR3, \% (n) & $30.2(19 / 63)$ & $95.5(640 / 670)$ & - & 38.8 (19/49) \\
\hline $95 \% \mathrm{Cl}$ & $19.2-43.0$ & $93.7-97.0$ & - & $25.2-53.8$ \\
\hline
\end{tabular}

Abbreviations: $\mathrm{Cl}$, confidence interval; NPV, negative predictive value; PPV, positive predictive value.

cancer survivors are frequently monitored by cystoscopy, it is possible that the $F G F R 3$ assay may detect the presence of a cancer before it is visible by cystoscopy. ${ }^{5-7,13}$ In support of this idea, a recent study found that patients positive for an FGFR 3 mutation in their urine but who were considered cancer-free by cystoscopy often had bladder cancer recurrence shortly thereafter. ${ }^{20}$ These findings suggest that patients who have FGFR3 mutant DNA in their urine may benefit from additional surveillance. In addition, given that the FGFR3 assay can identify patients with low-grade tumors, there may be advantages to using this assay in conjunction with other assays that are typically more sensitive for high grade and stage tumors, such as cytology. ${ }^{22}$ In fact, a recent study found that the combination of FGFR 3 and cytology had a specificity of $99.5 \%$ and a PPV of $87.5 \%$ for diagnosing bladder cancer in patients with microhematuria or macrohematuria. ${ }^{12}$

Cystoscopic follow-up for nonmuscle-invasive bladder cancer is the main form of surveillance within the urologic community. ${ }^{13}$ Due to the high frequency of local recurrence and

Table 4 Summary of multianalyte diagnostic readout assay performance characteristics by tumor TNM stage and grade

\begin{tabular}{|c|c|c|c|}
\hline $\begin{array}{l}\text { Grade, } \\
\text { n (\%) }\end{array}$ & $\begin{array}{l}\text { Sensitivity } \\
\text { by grade/stage }\end{array}$ & $\begin{array}{l}\text { Specificity for } \\
\text { all cancer- } \\
\text { negative } \\
\text { subjects }\end{array}$ & $\begin{array}{l}\text { NPV by grade/ } \\
\text { stage versus all } \\
\text { cancer-negative } \\
\text { subjects }\end{array}$ \\
\hline I & $3 \mathrm{I} / 37(83.8)$ & $231 / 670(34.5)$ & $231 / 237(97.5)$ \\
\hline $95 \% \mathrm{Cl}$ & $68.0-93.8$ & $30.9-38.2$ & $94.6-99.1$ \\
\hline II & $8 / 8(100.0)$ & $231 / 670(34.5)$ & $23 I / 23 I(100.0)$ \\
\hline $95 \% \mathrm{Cl}$ & $63.1-100.0$ & $30.9-38.2$ & $98.4-100.0$ \\
\hline III & $16 / 16(100.0)$ & $231 / 670(34.5)$ & $23 I / 23 I(100.0)$ \\
\hline $95 \% \mathrm{Cl}$ & $79.4-100.0$ & $30.9-38.2$ & $98.4-100.0$ \\
\hline Unknown & $2 / 2(100.0)$ & $231 / 670(34.5)$ & $23 I / 23 I(100.0)$ \\
\hline $95 \% \mathrm{Cl}$ & $15.8-100.0$ & $30.9-38.2$ & $98.4-100.0$ \\
\hline \multicolumn{4}{|l|}{ Stage } \\
\hline $\mathrm{Ta}$ & $43 / 49(87.8)$ & $231 / 670(34.5)$ & $231 / 237(97.5)$ \\
\hline $95 \% \mathrm{Cl}$ & $75.2-95.4$ & $30.9-38.2$ & $94.6-99.1$ \\
\hline TI & $8 / 8(100.0)$ & $231 / 670$ (34.5) & $23 I / 23 I(100.0)$ \\
\hline $95 \% \mathrm{Cl}$ & $63.1-100.0$ & $30.9-38.2$ & $95.4-100.0$ \\
\hline Tis & $5 / 5(100.0)$ & $231 / 670(34.5)$ & $23 I / 23 I(100.0)$ \\
\hline $95 \% \mathrm{Cl}$ & $47.8-100.0$ & $30.9-38.2$ & $95.4-100.0$ \\
\hline Unknown & $\mathrm{I} / \mathrm{I}(100.0)$ & $231 / 670(34.5)$ & $23|/ 23|(100.0)$ \\
\hline $95 \% \mathrm{Cl}$ & $2.5-100.0$ & $30.9-38.2$ & $95.4-100.0$ \\
\hline
\end{tabular}

Note: 'Biomarker combination included NID2, FGFR3, VIM, and MMP-2. Abbreviations: $\mathrm{Cl}$, confidence interval; NPV, negative predictive value. the potential for stage progression, the American Urological Association guidelines recommend lifelong follow-up for patients with nonmuscle-invasive bladder cancer. ${ }^{23}$ The most commonly utilized strategy involves patient assessment every 3 months for the first 2 years following the initial diagnosis, followed by every 6 months for an additional 2-3 years, and then annually thereafter. ${ }^{5,13}$ Reducing the number of cystoscopies administered to screen for recurrent bladder cancer may reduce patient burden and increase compliance. ${ }^{24}$ The high NPV of the four biomarker assay $(97.5 \%)$ may assist in the successful identification of patients with a very low probability of recurrent disease.

\section{Conclusion}

In this study, the noninvasive, urine-based multianalyte diagnostic readout assay uses a combination of four biomarkers to achieve high NPV for identifying a subgroup of patients who are unlikely to have bladder cancer recurrence and FGFR3 to identify another subgroup with a high likelihood of recurrence. This approach provides a noninvasive, urine-based assay to triage a population of patients undergoing routine monitoring for recurrence and correctly identify those patients who should be further evaluated with additional diagnostic procedures.

\section{Acknowledgments}

The authors would like to thank Elizabeth Goodwin for editorial support, Ann Murphy Legg for study design and oversight, and Angelo De Marzo for critical review of the manuscript. The authors would also like to acknowledge all our clinical collaborators in this study: Drs James Bailen, Yitzhak Berger, Daniel Burzon, James Cochran, Jeffrey Cohen, Jeffrey Dann, Bernard Hertzman, Evan Goldfischer, R Jeffrey Karnes, Donald Lamm, Daniel Saltzstein, Mark White, David Jablonski, Aaron Milbank, Joel Bass, Barrett Cowan, Michael Perrotti, Paul Sieber, Jed Kaminetsky, Jonathan Taylor, S Robert Julian, Eugene Kramolowsky, Lawrence Fish, Gary Golberg, Jeffrey Sekula, Lewis Kriteman, Henry Ruiz, Lawrence Karsh, and Kenneth Kernen. 


\section{Disclosure}

CAF and APS are employees of Predictive Biosciences. NDS has no conflict of interest to disclose.

\section{References}

1. Jemal A, Bray F, Center MM, Ferlay J, Ward E, Forman D. Global cancer statistics. CA Cancer J Clin. 2011;61(2):69-90.

2. Gazzaniga P, Gradilone A, de Berardinis E, et al. Prognostic value of circulating tumor cells in nonmuscle invasive bladder cancer: a CellSearch analysis. Ann Oncol. February 28, 2012;23(9):2352-2356.

3. Millan-Rodriguez F, Chechile-Toniolo G, Salvador-Bayarri J, Palou J, Algaba F, Vicente-Rodriguez J. Primary superficial bladder cancer risk groups according to progression, mortality and recurrence. J Urol. 2000;164(3 Pt 1):680-684.

4. Sugano K, Kakizoe T. Genetic alterations in bladder cancer and their clinical applications in molecular tumor staging. Nat Clin Pract Urol. 2006;3(12):642-652.

5. Babjuk M, Oosterlinck W, Sylvester R, et al. EAU guidelines on nonmuscle-invasive urothelial carcinoma of the bladder, the 2011 update Eur Urol. 2011;59(6):997-1008.

6. Scher H, Bahnson R, Cohen S, et al. NCCN urothelial cancer practice guidelines. National Comprehensive Cancer Network. Oncology (Williston Park). 1998;12(7A):225-271.

7. Brausi M, Witjes JA, Lamm D, et al. A review of current guidelines and best practice recommendations for the management of nonmuscle invasive bladder cancer by the International Bladder Cancer Group. J Urol. 2011;186(6):2158-2167.

8. Fenlon HM, Bell TV, Ahari HK, Hussain S. Virtual cystoscopy: early clinical experience. Radiology. 1997;205(1):272-275.

9. Hong YM, Loughlin KR. Economic impact of tumor markers in bladder cancer surveillance. Urology. 2008;71(1):131-135.

10. Duggan B, Williamson K. Molecular markers for predicting recurrence, progression and outcomes of bladder cancer (do the poster boys need new posters?). Curr Opin Urol. 2004;14(5):277-286.

11. Fernandez CA, Millholland JM, Zwarthoff EC, Feldman AS, Karnes RJ, Shuber AP. A noninvasive multi-analyte diagnostic assay: combining protein and DNA markers to stratify bladder cancer patients. Research and Reports in Urology. 2012;4:17-26.

12. Karnes RJ, Fernandez CA, Shuber AP. A non-invasive multi-analyte urine based diagnostic assay for urothelial cancer of the bladder in the evaluation of hematuria. Mayo Clinic Proc. 2012;87(9):835-842.
13. Sengupta S, Blute ML. The management of superficial transitional cell carcinoma of the bladder. Urology. 2006;67(3 Suppl 1):48-54.

14. Fernandez CA, Wszolek MF, Loughlin KR, Libertino JA, Summerhayes IC, Shuber AP. A novel approach to using matrix metalloproteinases for bladder cancer. J Urol. 2009;182(5):2188-2194.

15. Costa VL, Henrique R, Danielsen SA, et al. Three epigenetic biomarkers, GDF15, TMEFF2, and VIM, accurately predict bladder cancer from DNA-based analyses of urine samples. Clin Cancer Res. 2010;16(23):5842-5851.

16. Kompier LC, van der Aa MN, Lurkin I, et al. The development of multiple bladder tumour recurrences in relation to the FGFR3 mutation status of the primary tumour. $J$ Pathol. 2009;218(1):104-112.

17. van Oers JM, Lurkin I, van Exsel AJ, et al. A simple and fast method for the simultaneous detection of nine fibroblast growth factor receptor 3 mutations in bladder cancer and voided urine. Clin Cancer Res. 2005; 11(21):7743-7748.

18. van Oers JM, Zwarthoff EC, Rehman I, et al. FGFR3 mutations indicate better survival in invasive upper urinary tract and bladder tumours. Eur Urol. 2009;55(3):650-657.

19. van Rhijn BW, Lurkin I, Radvanyi F, Kirkels WJ, van der Kwast TH, Zwarthoff EC. The fibroblast growth factor receptor 3 (FGFR3) mutation is a strong indicator of superficial bladder cancer with low recurrence rate. Cancer Res. 2001;61(4):1265-1268.

20. Zuiverloon TC, van der Aa MN, van der Kwast TH, et al. Fibroblast growth factor receptor 3 mutation analysis on voided urine for surveillance of patients with low-grade non-muscle-invasive bladder cancer. Clin Cancer Res. 2010;16(11):3011-3018.

21. Horstmann M, Pastchan O, Hennenlotter J, et al. Combinations of urine-based tomour markers in bladder cancer surveillance. Scand $J$ Urol Nephrol. 2009;43:461-466.

22. Bastacky S, Ibrahim S, Wilczynski SP, Murphy WM. The accuracy of urinary cytology in daily practice. Cancer. 1999;87(3):118-128.

23. Hanno PM, Burks DA, Clemens JQ, et al. AUA guideline for the diagnosis and treatment of interstitial cystitis/bladder pain syndrome. J Urol. 2011;185(6):2162-2170.

24. Chamie K, Saigal CS, Lai J, et al. Compliance with guidelines for patients with bladder cancer: variation in the delivery of care. Cancer. 2011;117(23):5392-5401. 


\section{Supplemental table}

Table SI Sequence of primers for multianalyte diagnostic readout assay

\begin{tabular}{|c|c|c|}
\hline Assay & Reagent & Sequence \\
\hline \multirow[t]{6}{*}{ FGFR3 primary PCR } & Exon 7 forward & 5' GCG GTC CCA AAA GGG TCA GTA CAG TGG CGG TGG TGG TGA GGG AG 3’ \\
\hline & Exon 7 reverse & 5' GCG GTC CCA AAA GGG TCA GTA CGC ACC GCC GTC TGG TTG G 3' \\
\hline & Exon 10 forward & 5' GCG GTC CCA AAA GGG TCA GTA CGG TCT GGC CCT CTA GAC TCA 3' \\
\hline & Exon 10 reverse & 5' GCG GTC CCA AAA GGG TCA GTA CGA AGA AGC CCA CCC CGT A 3' \\
\hline & Exon 15 forward & 5' GCG GTC CCA AAA GGG TCA GTA CCC TGC CCT GAG ATG CT 3’ \\
\hline & Exon 15 reverse & 5' GCG GTC CCA AAA GGG TCA GTA CCG TCC TAC TGG CAT GAC C 3' \\
\hline \multirow[t]{14}{*}{ FGFR3 mutation detection } & Exon 7 forward & 5' GCG TCA TCT GCC CCC A 3' \\
\hline & Exon 7 reverse & 5' CAC CGC CGT CTG GTT G 3' \\
\hline & Exon 7 LNA & 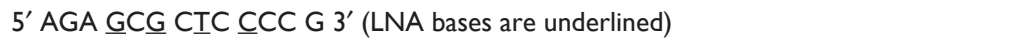 \\
\hline & Exon 7 probe & 5' FAM-CCC GCC TGC AGG ATG GGC CGG T-lowa Black FQ 3' \\
\hline & Exon 10 forward & 5' GGC CTC AAC GCC CAT GT 3' \\
\hline & Exon IOA reverse & 5' TAG CTG AGG ATG CCT GCA TA 3' \\
\hline & Exon $\mathrm{IOB}$ reverse & 5' CCG TAG CTG AGG ATG CCT G 3' \\
\hline & Exon IOA LNA & 5' ATA CAC $\underline{A C T}$ GCC C CGC CT 3' (LNA bases are underlined) \\
\hline & Exon IOB LNA & 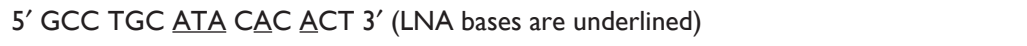 \\
\hline & Exon 10 probe & 5' FAM-CCG AGG AGG AGC TGG TGG AGG CTG AC-lowa Black FQ 3' \\
\hline & Exon 15 forward & 5' CAA TGT GCT GGT GAC CGA G 3' \\
\hline & Exon 15 reverse & 5' CCG GGC TCA CGT TGG TC 3' \\
\hline & Exon I5 LNA & 5' GGT CGT CTT CTT GTA GT 3' (LNA bases are underlined) \\
\hline & Exon 15 probe & 5' FAM-CTG GCC CGG GAC GTG CAC AAC CTC GAC T-lowa Black FQ 3' \\
\hline \multirow[t]{2}{*}{ Nid2 } & Nid forward & 5’ GCG GTT TTT AAG GAG TTT TAT TTT C 3’ \\
\hline & Nid reverse & 5' CTA CGA AAT TCC CTT TAC GCT 3' \\
\hline \multirow[t]{3}{*}{ VIM } & VIM forward & 5' GCG GTC CCA AAA GGG TCA GTA CTT CGG GAG TTA GTT CGC GTT 3' \\
\hline & VIM reverse & 5' GCG GTC CCA AAA GGG TCA GTA CAC CGC CGA ACA TCC TAC GA 3’ \\
\hline & VIM probe & 5' ACG AAA AAT AAC GAT AAC CTA AAC GAC GAC GA 3' \\
\hline \multirow[t]{3}{*}{ ACTB } & ACTB forward & 5’ TAG GGA GTA TAT AGG TTG GGG AAG TT 3' \\
\hline & ACTB reverse & 5' AAC ACA CAA TAA CAA ACA CAA ATT CAC $3^{\prime}$ \\
\hline & ACTB probe & 5' TGG GGT GGT GAT GGA GGA GGT TTA GTA AGT TTT TT 3' \\
\hline
\end{tabular}

Abbreviations: LNA, locked nucleic acid; PCR, polymerase chain reaction.

Research and Reports in Urology

\section{Publish your work in this journal}

Research and Reports in Urology is an international, peer-reviewed, open access journal publishing original research, reports, editorials, reviews and commentaries on all aspects of adult and pediatric urology in the clinic and laboratory including the following topics: Pathology, pathophysiology of urological disease; Investigation and treatment of

\section{Dovepress}

urological disease; Pharmacology of drugs used for the treatment of urological disease. The manuscript management system is completely online and includes a very quick and fair peer-review system, which is all easy to use. Visit http://www.dovepress.com/testimonials.php to read real quotes from published authors. 